\title{
The Influence of Emotional Labor on Turnover Intention of Hotel Employees: Mediating Effect of Emotional Dissonance
}

\author{
Guifang Fu1, Ronglu Shen'1, Yimei Wei ${ }^{2 *}$ \\ ${ }^{1}$ Department of Applied Psychology, School of Public Administration, Guangdong University of Foreign Studies, Guangzhou, \\ China \\ ${ }^{2}$ Mental Health Education Center, Students' Affairs Division, Northeast Normal University, Changchun, China \\ Email: ^48417319@qq.com
}

How to cite this paper: Fu, G. F., Shen, R. L., \& Wei, Y. M. (2020). The Influence of Emotional Labor on Turnover Intention of Hotel Employees: Mediating Effect of Emotional Dissonance. Open Journal of Business and Management, 8, 1089-1102. https://doi.org/10.4236/ojbm.2020.83069

Received: February 15, 2020

Accepted: April 18, 2020

Published: April 21, 2020

Copyright $\odot 2020$ by author(s) and Scientific Research Publishing Inc. This work is licensed under the Creative Commons Attribution International License (CC BY 4.0).

http://creativecommons.org/licenses/by/4.0/

\begin{abstract}
Based on the theory of emotional labor, this study explored the relationship between emotional labor and turnover intention of hotel staff by constructing intermediary effect model. The employees of different hotels in Guangdong province in China were investigated by emotional labor scale, emotional dissonance scale and turnover intention scale. The results showed that the hotel staff paid more deep acting than surface acting in emotional labor; emotional dissonance and turnover intention were in the middle level. There were differences in the deep acting of employees in education level and job position; emotional dissonance had significant differences in education level; and turnover intention had significant differences in working years. The surface acting of emotional labor had a significant positive correlation with emotional dissonance and turnover intention. Emotional dissonance had a completely mediating effect between surface acting and turnover intention.
\end{abstract}

\section{Keywords}

Emotional Labor, Emotional Dissonance, Turnover Intention, Hotel Employees

\section{Introduction}

Emotional labor as the management of emotions and feelings is carried out by individuals in order to show perceptible facial expressions and physical movements in front of the public. Grandey (2000) thought emotional labor is the psychological adjustment and processing of employees' emotional feelings and 
emotional expression in order to achieve organizational goals. According to the different interpretation of the concept of emotional labor, the researchers put forward the dimension of emotional labor. Hochschild (1983) suggested that emotional labor could be divided into two dimensions, including surface acting and deep acting. Surface acting refers to the employees only by changing the external behavior that can be detected or directly seen (such as facial expression, pronunciation and intonation, body movements, etc.) to show the emotions required by the organization, but their inner emotions and feelings have not changed in reality. Deep acting refers to employees' continuous self-revision to make their inner emotions and feelings consistent with the emotional behaviors required by the organization. Grandey (2000) believes that surface acting is the regulation of emotional expression by employees, and deep acting is the regulation of emotional feelings. Diefendorff et al. (2005) have a similar view, which adds an additional dimension to the research of Hochschild (1983)'s theory of two-dimensional structure of emotional labor. That is, the real emotional expression of (the expression of) naturally felt emotions. So this study believes that emotional labor is the positive emotion paid by individuals and the psychological adjustment and processing of emotional feelings and emotional expression in the process of work, including surface acting and deep acting.

Diefendorff et al. (2005) pointed out that emotional dissonance is the result of emotional labor, and emotional dissonance will occur when the emotion expressed by employees conflicts with the inner real emotion. Organization and work roles have certain constraints on the expression and behavior of individual emotional feelings, and employees need to show appropriate emotions in accordance with their own roles according to the rules and requirements. However, the internal emotional state and feeling of the individual are not necessarily consistent with the requirements of the organization. When the real emotional feeling of the heart conflicts with the emotional feeling required to be expressed in the workplace, psychological discomfort and tension will often occur, so as to emotional dissonance. Employees in the service industry (such as hotel employees) require a lot of emotional labor for a long time, which can easily lead to emotional dissonances. Some studies have found that emotional dissonances can damage the emotional function of individuals, and even cause emotional dissonances, affecting the mental health of individuals, which will have serious adverse consequences for individuals in the long run. Individuals with emotional impairment or psychological problems tend to reduce work efficiency, affect work performance, and have an impact on organizational performance, while the more serious may also endanger themselves or others.

Turnover intention refers to the intention or idea that an organization employee wants to leave the original work unit or organization. Turnover refers to the fact that the employee has left the organization and is an act that has taken place, including voluntary and involuntary turnover. Voluntary departure is when an employee leaves the organization on his or her own initiative for personal reasons, such as resignation; an involuntary departure is when an em- 
ployee is forced to leave his or her organization, such as being dismissed. The research shows that the turnover behavior of employees will have a direct and indirect impact on the organization. It is generally believed that the involuntary turnover of employees is conducive to the development of the organization, while voluntary turnover is not conducive to the development of the organization. This survey studies the voluntary departure of employees, that is, the intention of employees to leave on their own initiative, according to the view that intention is the key index of behavior (Richer, Blanchard, \& Vallerand, 2002). Similarly, Griffeth, Hom, \& Gaertner (2000) found that turnover intention can predict turnover behavior well.

Diefendorff et al. (2005) believe that the surface acting and deep acting of emotional labor are compensative behaviors, which have negative effects on individuals and cause emotional dissonances. Li Hongju et al. (2007) summarized previous studies on emotional labor, and found that emotional labor affects mental health, resulting in three possible results: emotional coordination, emotional dissonances and emotional deviation. Bozionelos and Kiamou (2008) found that there is a significant positive correlation between surface acting and turnover tendency of emotional labor. There is no correlation between deep acting and turnover intention. Based on the resource conservation theory of Hobfoll (2001), Mishra and Bhatnagar (2010) studied the medical representatives and found that there was a significant positive correlation between emotional dissonances and turnover intention. Liu Qinwei (2014) found that emotional labor affects emotional dissonance and turnover intention, and emotional dissonance plays an intermediary role between emotional labor and turnover intention.

At present, there are the following problems in the study of emotional labor. First, although there are a lot of empirical studies on emotional labor in China, there are still some contradictions between many research results due to the differences in the industry. Second, there are few studies on emotional labor of hotel employees in China, especially on the relationship between emotional labor, mental health and turnover intention. Third, due to the differences of cultural background, the results of foreign research on emotional labor of hotel employees may not be applicable to the local situation of our country.

To sum up, in order to explore the relationship and mechanism among emotional labor, emotional dissonance and turnover intention, this study is based on emotional labor theory and takes hotel employees as subjects to construct an intermediary model (Figure 1).

\section{Method}

\subsection{Participants}

The subjects in this study were mainly from a number of hotel employees. A total of 136 valid questionnaires were collected and the recovery rate was $100 \%$. The demographic characteristics are shown in Table 1. 


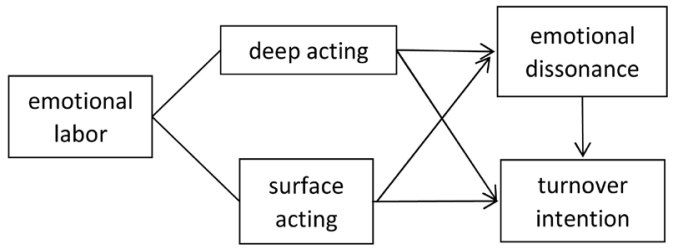

Figure 1. Intermediary model.

Table 1. Participants.

\begin{tabular}{|c|c|c|c|}
\hline & & $\mathrm{n}$ & $\%$ \\
\hline \multirow{2}{*}{ gender } & male & 62 & 44.9 \\
\hline & female & 76 & 55.1 \\
\hline \multirow{5}{*}{ age } & $<20$ & 21 & 15.2 \\
\hline & $20-29$ & 53 & 38.4 \\
\hline & $30-39$ & 15 & 10.9 \\
\hline & $40-49$ & 34 & 24.6 \\
\hline & $\geq 50$ & 15 & 10.9 \\
\hline \multirow{5}{*}{ educational status } & junior & 9 & 6.5 \\
\hline & senior & 38 & 27.5 \\
\hline & junior college education & 60 & 43.5 \\
\hline & undergraduate & 29 & 21 \\
\hline & postgraduate & 2 & 1.4 \\
\hline \multirow{4}{*}{ working position } & general staff & 91 & 65.9 \\
\hline & grass-roots managers & 21 & 15.2 \\
\hline & middle managers & 20 & 14.5 \\
\hline & senior management & 6 & 4.3 \\
\hline \multirow{4}{*}{ working life } & $\leq 3$ years & 67 & 48.6 \\
\hline & $4-6$ years & 16 & 11.6 \\
\hline & 7 - 12 years & 17 & 12.3 \\
\hline & $\geq 13$ years & 38 & 27.5 \\
\hline
\end{tabular}

\subsection{Instruments}

Emotional Labor scale: Liu Qinwei (2014) was used to translate and revise the emotional Labor scale, which was originally compiled by Diefendorff et al. (2005). It has three dimensions: surface acting, deep acting and real emotional expression. In this study, surface acting and deep acting were selected to represent emotional labor. There are 11 topics, including 7 topics of surface acting and 4 topics of deep acting.

Emotional dissonance scale: Liu Qinwei (2014) was used to translate and adapt the emotional dissonance scale. There are five items, the higher the score, the 
higher the degree of emotional dissonance.

Turnover intention scale: Based on the turnover intention table compiled by Mobley et al. (1978), there are four questions in the questionnaire, and the higher the score is, the more obvious the turnover intention is. The scales were scored by Richter level 5.1 was very inconsistent, 5 was very consistent, and the subjects were required to complete the questionnaire according to their own actual situation.

In this study, Cronbach's a coefficient was used to test the reliability of emotional labor scale, emotional dissonance scale and turnover intention scale. As shown in Table 2, the Cronbach's a coefficients of each scale are greater than 0.7 , which indicates that the scale used in this study has good reliability and high reliability.

\subsection{Research Process}

A cross-sectional survey was conducted from January to April 2018. A convenience cluster sampling method was employed to produce a sample of hotel employee. All participants were recruited from Guangdong province. Everybody involved in this study will be told to participant voluntarily and could withdraw at any time. The participants answered a questionnaire through Wenjuanxing on the Internet. It took the respondents approximately $10 \mathrm{~min}$ to complete the anonymous questionnaire. A small was given to make up for the time spent on the survey.

\subsection{Data Processing Methodology}

The data collected in this study were processed and analyzed by SPSS 18.0 statistical software.

\section{Results}

\subsection{Reliability and Validity Analysis}

\subsubsection{Validity Analysis of Emotional Labor Scale}

As can be seen from Table 3, the observed values of Bartlett spherical degree test are 508.662 and KMO value is $0.746, P<0.0001$, which indicates that the variables are suitable for factor analysis.

The principal component analysis of the scale was carried out, and two factors

Table 2. KMO and spherical Bartlett tests of turnover intention scale.

\begin{tabular}{lcc}
\hline Kaiser-Meyer-Olkin measure of sampling adequacy & 0.622 \\
& Approx. Chi-Square & 178.056 \\
Ball shape test of Bartlett & df & 6 \\
& Sig. & $0.000^{* * *}$ \\
\hline
\end{tabular}

${ }^{* * *} P<0.001$ 
Table 3. Reliability analysis of scale.

\begin{tabular}{ccc}
\hline & Cronbach's a & $\mathrm{n}$ \\
\hline Emotional labor & 0.780 & 11 \\
Surface acting & 0.780 & 7 \\
Deep acting & 0.742 & 4 \\
Emotional dissonance & 0.762 & 5 \\
Turnover intention & 0.759 & 4 \\
\hline
\end{tabular}

were extracted. The eigenvalue of the first factor is 3.601, and the contribution rate of cumulative variance is $32.737 \%$, and that of the second factor is 2.210 , and the contribution rate of cumulative variance is $52.831 \%$. Factor 1 is named "surface acting", including 7 topics (A1 - A7), factor load is $0.542-0.814$, factor 2 is named "deep acting", including 4 topics (A8 - A9), factor load is 0.577 0.856 .

\subsubsection{Validity Analysis of Emotional Dissonance Scale}

From Table 4, it can be seen that the observed values of Bartlett spherical degree test are 332.683 and KMO values are $0.807, P<0.0001$, which indicates that the variables are suitable for factor analysis.

The principal component analysis of the scale showed that the factor load of topic 1 was only 0.178 , so the problem was deleted. After deleting title 1 , the observed values of Bartlett spherical degree test were 332.683 and $\mathrm{KMO}$ values were $0.807, P<0.0001$, which indicated that the variables were suitable for factor analysis. The remaining four questions were all loaded on one factor, and the loads on the four topics were all greater than 0.8 .

\subsubsection{Validity Analysis of Turnover Intention Scale}

From Table 5, it could be seen that the observed values of Bartlett spherical degree test were 178.056 and KMO value was $0.622, P<0.0001$, which indicated that the scale was suitable for factor analysis.

The principal component analysis of the scale shows that all the questions were loaded on one factor, and the factor load of the title was more than 0.6, which was between 0.608 and 0.912 .

\subsection{Description of Statistics and Related Analysis}

Emotional labor (surface acting and deep acting), emotional dissonance and turnover intention scores were between 1 and 5 . The higher the score of emotional labor, the more emotional labor; the higher the score of emotional dissonance, the more serious the emotional dissonance; the higher the score of turnover intention, the higher the turnover tendency. According to Table 6, the score of deep acting of hotel staff was higher than that of surface acting, which indicated that hotel employees paid more deep acting than surface acting in 
Table 4. KMO and spherical Bartlett tests.

\begin{tabular}{lcc}
\hline Kaiser-Meyer-Olkin measure of sampling adequacy & 0.746 \\
& Approx. Chi-Square & 508.662 \\
Ball shape test of Bartlett & df & 55 \\
& Sig. & $0.000^{* * *}$ \\
${ }_{* * * P<0.001 .}$ &
\end{tabular}

Table 5. First KMO and spherical Bartlett test of the emotional disorders scale.

\begin{tabular}{lcc}
\hline Kaiser-Meyer-Olkin measure of sampling adequacy & 0.807 \\
& Approx. Chi-Square & 332.683 \\
Ball shape test of Bartlett & df & 10 \\
& Sig. & $0.000^{* * *}$ \\
${ }_{* * * P<0.001 .}$
\end{tabular}

Table 6. Describe statistics and related analysis.

\begin{tabular}{ccccccc}
\hline & $M$ & $S D$ & $\begin{array}{c}\text { Surface } \\
\text { acting }\end{array}$ & $\begin{array}{c}\text { Deep } \\
\text { acting }\end{array}$ & $\begin{array}{c}\text { Emotional } \\
\text { dissonance }\end{array}$ & $\begin{array}{c}\text { Turnover } \\
\text { intention }\end{array}$ \\
\hline Surface acting & 3.57 & 0.65 & 1.00 & & & \\
Deep acting & 4.04 & 0.62 & $0.27^{* *}$ & 1.00 & & \\
Emotional dissonance & 3.33 & 0.74 & $0.52^{* *}$ & $-0.22^{*}$ & 1.00 & 1.00 \\
Turnover intention & 3.27 & 0.86 & $0.27^{* *}$ & 0.08 & $0.35^{*}$ &
\end{tabular}

emotional labor. The average score of emotional dissonance and turnover intention of hotel employees was slightly higher than 3 , which indicated that the emotional dissonance of hotel employees was in the middle level and the turnover intention was in the middle level.

According to Table 6, there was a significant positive correlation between the surface acting of emotional labor and emotional dissonance and turnover intention of hotel employees. There was a significant negative correlation between the deep acting of emotional labor and emotional dissonance, but there was no significant correlation between emotional labor and turnover intention. There was a significant positive correlation between emotional dissonance and turnover intention.

\subsection{Differences Analyses}

There were differences in the level of education and the position of work in the deep labor of employees. There were significant differences in the level of education among employees with emotional dissonances. There were significant differences in the turnover intention of employees in terms of working years (Table 7). 
Table 7. Differences analysis.

\begin{tabular}{|c|c|c|c|c|c|c|c|c|}
\hline & & \multirow{2}{*}{$M$} & \multicolumn{2}{|c|}{ Deep acting } & \multicolumn{2}{|c|}{$\begin{array}{l}\text { Emotional } \\
\text { dissonance }\end{array}$} & \multicolumn{2}{|c|}{$\begin{array}{l}\text { Turnover } \\
\text { intention }\end{array}$} \\
\hline & & & $F$ & $P$ & $F$ & $P$ & $F$ & $P$ \\
\hline \multirow{5}{*}{$\begin{array}{l}\text { educational } \\
\text { status }\end{array}$} & junior & 3.698 & \multirow{5}{*}{3.645} & \multirow{5}{*}{$0.008^{\star *}$} & \multirow{5}{*}{3.023} & \multirow{5}{*}{$0.020^{*}$} & \multirow{5}{*}{0.655} & \multirow{5}{*}{0.624} \\
\hline & senior & 3.456 & & & & & & \\
\hline & junior college education & 3.583 & & & & & & \\
\hline & undergraduate & 3.631 & & & & & & \\
\hline & postgraduate & 3.571 & & & & & & \\
\hline \multirow{4}{*}{$\begin{array}{l}\text { working } \\
\text { position }\end{array}$} & general staff & 3.571 & \multirow{4}{*}{2.842} & \multirow{4}{*}{$0.040^{*}$} & \multirow{4}{*}{2.118} & \multirow{4}{*}{0.101} & \multirow{4}{*}{1.693} & \multirow{4}{*}{0.172} \\
\hline & grass-roots managers & 3.674 & & & & & & \\
\hline & middle managers & 3.479 & & & & & & \\
\hline & senior managers & 3.429 & & & & & & \\
\hline \multirow{4}{*}{ working life } & $\leq 3$ years & 3.520 & \multirow{4}{*}{0.558} & \multirow{4}{*}{0.644} & \multirow{4}{*}{1.560} & \multirow{4}{*}{0.202} & \multirow{4}{*}{2.144} & \multirow{4}{*}{$0.048^{*}$} \\
\hline & $3-6$ years & 3.705 & & & & & & \\
\hline & 7 - 12 years & 3.681 & & & & & & \\
\hline & $\geq 13$ years & 3.538 & & & & & & \\
\hline
\end{tabular}

${ }^{\star} P<0.05,{ }^{* *} P<0.01$.

\subsection{Testing of Mediating Effects}

In order to test the hypothesis, the relationship among emotional labor (surface acting, deep acting), turnover intention and emotional dissonance was further explored. According to the test process of intermediary effect summarized by Wen Zhonglin et al. (2005), the variables were analyzed by regression analysis.

The results showed the relationship between deep acting and turnover intention was not significant, so the procedure of intermediary effect test was over, and emotional dissonance had no intermediary role between deep acting and turnover intention. The relationship between surface acting and turnover intention was significant, so the intermediary effect of emotional dissonance between surface acting and turnover intention was further verified (see Figure 2). The specific procedures for testing intermediary effects were as follows:

In the first step, taking surface acting as independent variable and turnover intention as dependent variable, regression analysis was carried out to test the coefficient $\mathrm{c}$. The results showed that the standard coefficient $\mathrm{c}$ of the regression equation was $0.268, P<0.01$, which indicated that the regression coefficient between surface acting and turnover intention was significant. Enter the second step of inspection.

In the second step, taking surface acting as independent variable and emotional dissonance as dependent variable, regression analysis was carried out to test the coefficient $a$. The results showed that the standard coefficient a of the regression equation was $0.53, P<0.01$, which indicated that the regression coefficient 


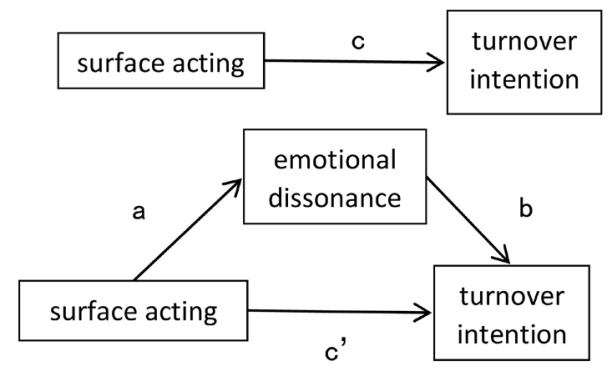

Figure 2. Model diagram of mediating action of emotional dissonance in surface acting and turnover intention.

between surface acting and emotional dissonance was significant. Enter the third step of inspection.

In the third step, the regression analysis was carried out with emotional dissonance as independent variable and turnover intention as dependent variable, and the test coefficient was $\mathrm{b}$. The results showed that the standard coefficient $\mathrm{b}$ of the regression equation was $0.265, P<0.01$, which indicated that the regression coefficient between emotional dissonance and turnover intention was significant.

The fourth step, check the coefficient $c$, judge whether it is a partial intermediary or a complete intermediary. The results showed that the c' value was 0.127 , $P>0.05$, and the test was not significant, so emotional dissonance played a complete intermediary role between surface acting and turnover intention (Table 8).

\section{Discussions}

\subsection{Hotel Staff's Deep Behavior Is at the Middle Level, and There Are Differences in Education Level and Job Position}

The research found that the deep acting of emotional labor of hotel staff was more than the superficial behavior, and was in the middle level. In the hotel industry, in order to meet the customer's requirements, the staff needs to pay a lot of emotional labor. The superficial behavior changes the perceived external behavior (such as facial expression, voice and intonation), while the deep acting has made the employee self-correction reach the same body and mind. The staff of the hotel needs to pay more deep-seated behaviors to adapt to the environment, and constantly improve the ability of self-correction to better serve others.

Different educational levels and jobs, the deep acting of hotel staff will also be very different. The higher the level of education and job position, the more deep acting of hotel staff. People with strong personal ability, their psychological capital is more adequate, the stronger the ability to regulate emotion. Wang Mengpei et al. (2019) found psychological capital and work motivation promote the degree of work investment through emotional labor strategy, at the same time, psychological capital has an impact on emotional labor strategy through work motivation, which also reflects this point of view. In addition to personal traits 
Table 8. The median effect of emotional dissonance $(M)$.

\begin{tabular}{cccc}
\hline & Standardized regression equation & \multicolumn{2}{c}{ Regression coefficient test } \\
\hline Step 1 & $Y=0.268 x$ & $S E=0.109$ & $t=3.222^{\star *}$ \\
Step 2 & $M=0.53 X$ & $S E=0.104$ & $t=7.244^{* *}$ \\
Step 3 & $S E=0.089$ & $t=2.769^{* *}$ \\
& $Y=0.265 M$ & $S E=0.126$ & $t=1.329$ \\
\hline
\end{tabular}

${ }^{* *} P<0.01$.

and abilities, the social environment is also another factor affecting emotional labor. For example, Valeriya Shapoval (2019) found that unfair distribution has an impact on the emotional labor of hotel employees, while unfair information and procedures have an impact on emotional labor, while the impact of unfair information and procedures on emotional labor is affected by gender.

\subsection{Emotional Labor Had a Significant Impact on Emotional Disorders}

This study showed that emotional labor of hotel employees would affect emotional dissonance, in which the surface acting of emotional labor was positively correlated with emotional dissonance, while deep acting was negatively correlated with emotional dissonance. This shows that the more surface acting employees pay, the more likely they are to cause emotional dissonances, while the more deep acting they pay, the less likely they are to cause emotional dissonances. This conclusion is the same as that obtained by taking the employees of commercial banks in China as the research object.

The significant effect of emotional labor on emotional dissonance of hotel staff can be explained by Hobfoll (2001) resource preservation theory. According to the theory of resource preservation, the individual pressure is caused by three aspects, namely, the loss of resources, the threat of existing resources and the imbalance of income and expenditure of resources. Employees pay emotional labor, whether surface or deep acting, need to consume their own resources; when resources are damaged, there will be pressure, long-term stress will easily lead to individual emotional dissonances.

When hotel staffs pay surface acting, they only change their external behavior according to the requirements and norms of the organization, but their inner emotions and attitudes have not changed. Based on Festinger (1957) cognitive disorder theory, when an individual's attitude or behavior conflicts, there will be discomfort and disorder. When employees' external behavior is inconsistent with their internal emotional attitude, it often leads to individual psychological tension, so the more surface acting they pay, the more likely they are to cause individual emotional dissonance.

On the contrary, hotel employees pay deep acting, which means that they are constantly revising their internal emotional attitude and trying to make their 
true emotions consistent with their external behavior. According to the theory of cognitive disorder, when an individual has cognitive disorder, he can reduce his inner discomfort by changing his own attitude or behavior. Therefore, the more deep acting employees pay, the less likely they are to cause emotional dissonances.

\subsection{The Relationship between Deep and Surface Behaviors of Emotional Labor and Turnover Intention}

This study found that there was a positive correlation between surface acting and turnover intention of hotel employees, but there was no correlation between deep acting and turnover intention. According to Hobfoll's (2001) theory of resource preservation, the imbalance of income and expenditure of individual resources is one of the causes of stress. Hotel staff pay emotional labor, whether it is surface acting or deep acting need to lose their own resources; if the lost resources are not timely and adequate supplement, will cause individual resources imbalance. When the employee pays the superficial behavior of emotional labor, because of the conflict between internal emotion and external behavior, the psychological resources are likely to be lost but not replenished, resulting in the imbalance of resources, causing discomfort and pressure; and the deep acting of employees who pay emotional labor, although their own resources will also be depleted, but because of the timely adjustment and correction of their own resources have been timely replenished, did not cause the imbalance state of deficit. On this basis, individuals always strive to maintain and protect what they consider valuable resources and minimize the loss of resources. In order to reduce the damage of their own resources and avoid the psychological pressure and discomfort caused by the loss of resources and the imbalance of income and expenditure of resources, employees who pay a large number of surface actings are likely to produce a series of work withdrawal behaviors and even turnover tendencies. On the contrary, employees who pay deep acting are replenished in a timely manner and may not need to reduce their inner discomfort through work withdrawal behavior.

The surface acting of emotional labor has an impact on turnover intention, which is consistent with the results of previous studies. However, there are still disputes and contradictions on whether the deep acting will affect the turnover intention. Some studies suggest that deep acting has a significant negative effect on turnover intention, because deep acting as a positive way to regulate the imbalance of resources, deep acting can have a positive effect, but Bozionelos and Kiamou (2008) study found that deep acting has no effect on turnover intention, but when interacting with emotional labor intensity, it will have a significant negative impact on turnover intention. So will different intensities of deep acting have an impact on turnover intention? Is this effect positive or negative? Will there be differences due to different social and cultural backgrounds? This problem needs to be further discussed in future research. 


\subsection{The Mediating Effect of Emotional Disorder between Emotional Labor and Turnover Intention}

This study also found that emotional dissonance will affect turnover intention, and emotional dissonance has a complete intermediary role between surface acting and turnover intention of emotional labor.

The more surface acting employees pay in emotional labor, the more likely they are to produce inconsistency between internal emotional attitude and external behavior, resulting in inner conflict and discomfort, resulting in emotional dissonance, while when employees pay deep acting, internal emotional attitude is adjusted and corrected, which is not easy to cause emotional dissonance. Therefore, the surface acting of hotel staff is likely to lead to emotional dissonances, while deep acting will reduce the occurrence of emotional dissonances.

At the same time, in order to balance the self-resources and reduce the psychological pressure caused by the emotional dissonance, the individual will generate the withdrawal behavior; and the separation behavior is one of the performances of the job withdrawal behavior, and the separation tendency is the key index of the separation behavior. Therefore, the mood disorder has a certain influence on the employee's turnover tendency.

\section{Conclusion}

In order to understand the status and relationship between emotional labor, emotional dissonance and turnover intention, the employees of different hotels in Guangdong province in China were surveyed by emotional labor scale, emotional dissonance scale and turnover intention scale. The results showed that the hotel staff paid more deep acting than surface acting in emotional labor; emotional dissonance and turnover intention were in the middle level. There were differences in the deep acting of employees in education level and job position; emotional dissonance had significant differences in education level; and turnover intention had significant differences in working years. The surface acting of emotional labor had a significant positive correlation with emotional dissonance and turnover intention. Emotional dissonance had a completely mediating effect between surface acting and turnover intention.

According to this study it is very necessary for employees and employer in the hotel industry and society to pay attention to the problems of emotional labor, especially deep acting of employees. This research has strong social practice significance and theoretical value. Based on this research results, some advices for hotel personnel management are as following. Firstly, be concerned about emotional labor and provide trainings about emotional labor and strategies for hotel employees. Secondly, attach importance on psychological satisfaction and emotional dissonance of employees and implement EAP service. Thirdly, pay attention to turnover intention of employees, and take timely action to retain good staffs and improve management efficiency.

Future research should adopt experimental methods, consider more economic 
and social variables, further explore the psychological mechanism of emotional dissonance and turnover intention, and establish operational procedures for prevention and intervention of turnover intention of employees in the hotel industry. This study explored the mediating role of emotional disorders between emotional labor and turnover intention, which is innovative to some extent, but also insufficient; for example, the sample size needs to be increased.

\section{Acknowledgements}

This work was supported by The National Social Science Fund of China [grant number 16BSH094].

\section{Conflicts of Interest}

The authors declare no conflicts of interest regarding the publication of this paper.

\section{References}

Bozionelos, K., \& Kiamou, K. (2008). Emotion Work in the Hellenic Frontline Services Environment: How It Relates to Emotional Exhaustion and Work Attitudes. International Journal of Human Resource Management, 19, 1108-1130. https://doi.org/10.1080/09585190802051410

Diefendorff, J. M., Croyle, M. H., \& Gosserand, R. H. (2005). The Dimensionality and Antecedents of Emotional Labor Strategies. Journal of Vocational Behavior, 66, 339-357. https://doi.org/10.1016/j.jvb.2004.02.001

Festinger, L. (1957). A Theory of Cognitive Dissonance (pp. 164-165). Redwood City, CA: Stanford University Press.

Grandey, A. A. (2000). Emotion Regulation in the Workplace: A New Way to Conceptualize Emotional Labor. Journal of Occupational Health Psychology, 5, 95-110. https://doi.org/10.1037/1076-8998.5.1.95

Griffeth, R. W., Hom, P. W., \& Gaertner, S. (2000). A Meta-Analysis of Antecedents and Correlates of Employee Turnover: Update, Moderator Tests, and Research Implications for the Next Millennium. Journal of Management, 26, 463-488. https://doi.org/10.1177/014920630002600305

Hobfoll, S. E. (2001). The Influence of Culture, Community, and the Nested-Self in the Stress Process: Advancing Conservation of Resources Theory. Applied Psychology, 50, 337-421. https://doi.org/10.1111/1464-0597.00062

Hochschild, A. R. (1983). The Managed Heart. Political Science Quarterly, 561, 8-26.

Li, H. J., Xu, Y., \& Zhang, H. Y. (2007). Review and Prospect of Emotional Labor Research. Chinese Journal of Clinical Psychology, 15, 409-411.

Liu, Q. W. (2014). Research on the Influence of Emotional Labor on Employees' Job Happiness and Turnover Intention. Master Thesis, Changsha: Hunan University.

Mishra, S. K., \& Bhatnagar, D. (2010). Linking Emotional Dissonance and Organizational Identification to Turnover Intention and Emotional Well-Being: A Study of Medical Representatives in India. Human Resource Management, 49, 401-419. https://doi.org/10.1002/hrm.20362

Mobley, W. H., Horner, S. O., \& Hollingsworth, A. T. (1978). An Evaluation of Precur- 
sors of Hospital Employee Turnover. Journal of Applied Psychology, 63, 408-414. https://doi.org/10.1037/0021-9010.63.4.408

Richer, S. F., Blanchard, C., \& Vallerand, R. J. (2002). A Motivational Model of Work Turnover. Journal of Applied Social Psychology, 32, 2089-2113. https://doi.org/10.1111/j.1559-1816.2002.tb02065.x

Valeriya, S. (2019). Organizational Injustice and Emotional Labor of Hotel Front-Line Employees. International Journal of Hospitality Management, 78, 112-121. https://doi.org/10.1016/j.ijhm.2018.10.022

Wang, M. P., Li, W. J., \& Wang, H. Y. (2019). The Influence of Teachers' Psychological Capital and Work Motivation on Work Input: The Intermediary Effect of Emotional Labor Strategy. Psychological Research, 12, 252-261.

Wen, Z. L., Hou, J. T., \& Zhang, L. (2005). Comparison and Application of Regulatory Effect and Intermediary Effect. Acta Psychologica Sinica, 37, 268-274. 